because of effective neonatal life-saving surgery. Hodgson and Yau from Hong Kong give a most useful practical account of the techniques involved in the anterior approaches to the spine.

Salter of Toronto discusses congenital hip disorders including an account of his own innominate osteotomy which is proving so useful in treating congenital dislocations in which diagnosis has still unfortunately been delayed.

Finally the surgery of osteoarthritis is discussed by Helfet and D'Aubigné' Helfet gives his views on the part played by meniscus tears in the knee joint, and D'Aubigné assesses the present position in relation to the hip joint.

The book is well produced with clear illustrations and is strongly recommended to all those who work in the absorbing field of the locomotor system.

\section{Paget's Disease of Bone.}

By Hugh C. Barry. Pp. 196, illustrated. Edinburgh and London: E. \& S. Livingstone, 1969. 80s.

At a time little short of a century following the original description of Paget's disease of bone, it is vastly instructive and only a little depressing to read this book, which is both an authoritative review of the present state of knowledge about Paget's disease and a frank account of how far we have yet to go in understanding its aetiology and mastering its complications.

Following a lively historical survey, Mr Barry discusses the condition under the usual chapter headings, with numerous illustrations and X-rays of good quality, and the chapters on pathology, medical aspects, treatment and neoplastic change merit special consideration. From the first two of these it emerges that there is no really new information to disturb the view of Albright and Reifenstein (1948) that Paget's is not a generalized bone disease but consists of focal lesions be they ever so numerous and widespread, and the aetiology remains totally unknown. Treatment in these circumstances must be a symptomatic exercise and it is useful to be reminded of what radiotherapy has to offer, even if the techniques and dosages suggested may not find universal support among radiotherapists.

The final chapter, on neoplastic change, offers a discussion based on a series of 116 cases and compares interestingly with Price and Goldie's (1969) series of 80 cases from Bristol and Leeds. The presence of a few giant-cell tumours in Barry's series indicate the possibility of a rare but welcome variation in the dismal prognosis usually accompanying sarcoma in Paget's disease.

This book must be regarded as a mid-term report on our attempts to solve the riddle posed by Paget in 1877; it is a most worthwhile addition to the literature.

\section{Proceedings of the First South African International Ophthal- mological Symposium}

Edited by M. H. Lunz. Pp. 374, illustrated. London: Butterworths, 1969. 140s.

This book is a report on the ophthalmological symposium held in Johannesburg in 1968, edited by Professor Maurice Luntz. It is divided into sections on Contact Lenses, Squint, Glaucoma, Cinematography, Retina, Anterior Segment, Corneal and Reconstructive Surgery. None of these sections is comprehensive in its field, but is rather a group of half a dozen or so original papers highlighting current ophthalmic problems and the authors' views on them.

Materials and methods used in contact lens practice are discussed with a good review of changes in procedure during the preceding 10 years. In squint, the optimum time for surgery is considered at some length, and various surgeons' preferred operative procedures are described. Toxins causing a rise in intra-ocular pressure are listed in one paper, and the use of plastic in glaucoma surgery is evaluated. The subsequent discussion makes the reader aware of the need for a new therapeutic approach to glaucoma. Communication is now so rapid, that many of the techniques described as novel in 1968 are already common practice in retinal detachment, corneal graft, and anterior segment surgery, and even some of the synthetic materials advocated, have been superseded. On the other hand, the place of the epikeratoprosthesis will not be fully evaluated for years to come, and the report of present clinical experience with it is of great interest.

This volume will remain a well deserved record of the symposium, and a tribute to the late Sir Benjamin Rycroft to whom it was dedicated.

\section{Homeostatic regulators.}

A CIBA Foundation Symposium held jointly with the Wellcome Trust.

Edited by G. E. Wolstenholme and Julie Knight. Pp. 327, illustrated. London: J. \& A. Churchill, 1969. $75 \mathrm{~s}$.

The differences between collated cellular activity and organic chemical existence lies in the organization and control operating in the former. Homeostatic regulators (which may be defined as regulating mechanisms which ensure stability of internal environment) can be considered to exercise their functions by employing several inhibitory opposing feed back systems. Failure in adaptive homeostatic control is bound to lead to functional disorders and irreversible pathological conditions; at worst it can lead to explosive developments which destroy the biological system. It is clear therefore that a Conference on 'Homeostatic Regulators' is bound to be not only useful but indeed essential. A Conference on these was held-jointly by the CIBA Foundation and the Wellcome Trust-in London last year and the Proceedings have now been published.

The overall field of cell growth regulating mechanisms is of course very large and ranges from dependence on biochemical systems to the integration of biological systems and in this context it is bound to involve integration of molecular mechanisms with general biological facets. The papers included homeostatic factors in cell population kinetics, chalones of the skin, growth facets of various tissues, clotting agents of tumours, control of gene expression in differentiating systems, relation between homeostasis and enzyme adaptation, the homeostatic potential of interferons and of lysozomes, regulation of antibody synthesis, the cell membrane and contact control, regulatory systems in cell culture and metabolic cooperation. Information concerning these individual systems can, of course, be obtained from several relevant books and other symposia. However, this Conference enabled comparison, contrast and collation of homeostatic controls at different levels of cell organization, e.g. the network of feed-back inhibitory mechanisms in biosynthetic enzymes and the regulatory mechanisms in the autonomic nervous system including the actions of acetylcholine, adrenaline and noradrenaline. Readers of the book soon appreciate the comprehensive effort and the high level of the papers involved. Nevertheless it is sad to see that no serious attempt was made to discuss at the molecular group level the ways in which a number of substances could be visualized to upset homeostatic regulation. After all, chemical group reactions are concerned with effective control! This criticism should not however be taken to detract effectively from the usefulness of the book. Every investigator in the field of growth and controls of cells and tissues should read and digest the contents of this book. Its importance lies not only in presenting up to date information concerning recent advances as well as understanding of their limitations; it is potent in acting as a nucleus for new ideas and interpretations in the various fields. 